\title{
Detection of fungal 18S rRNA sequences in conjunction with marine nematode 18S rRNA amplicons
}

\author{
Punyasloke Bhadury ${ }^{1,3,4, *}$, Paul D. Bridge ${ }^{2}$, Melanie C. Austen ${ }^{1}$, David T. Bilton ${ }^{3}$, \\ Gary R. Smerdon ${ }^{1}$ \\ ${ }^{1}$ Plymouth Marine Laboratory, Prospect Place, The Hoe, Plymouth PL1 3DH, UK \\ ${ }^{2}$ British Antarctic Survey, High Cross, Madingley Road, Cambridge CB3 0ET, UK \\ ${ }^{3}$ School of Biological Sciences, University of Plymouth, Drake Circus, Plymouth PL4 8AA, UK \\ ${ }^{4}$ Indian Institute of Science Education and Research Kolkata, Mohanpur Campus, PO BCKV Campus Main Office, \\ Mohanpur-741252, Nadia, West Bengal, India
}

\begin{abstract}
Free-living nematodes constitute an important component of estuarine and marine benthic ecosystems. Some marine and soil nematodes are known to harbor microbes, including symbiotic bacteria and fungi, in their external cuticle as well as internally. While assessing diversity of marine nematodes from southwest England using molecular approaches, we found evidence of coamplification of fungal 18S rRNA sequences in conjunction with nematode 18S rRNA sequences. Based on an 18S rRNA PCR-DGGE approach, 3 fungal clone types were detected alongside nematodes from 2 of 4 estuarine and marine sites in southwest England. At the phylogeny level, fungal clone type 1 belongs to Chaetothyriales while the other 2 clone types belong to Hypocreales. The fungal clones were co-amplified with specific marine nematode taxa indicating true ecological association rather than transient environmental contamination. The present study is the first to detect fungal 18S sequences in parallel with marine nematodes and opens up a new avenue of research for investigating ecological interactions between nematodes and fungi in the marine environment.
\end{abstract}

KEY WORDS: Marine nematodes $\cdot 18 \mathrm{~S}$ rRNA $\cdot$ DGGE $\cdot$ Fungi

\section{INTRODUCTION}

In estuarine and marine environments, free-living nematodes dominate the benthic meiofauna in terms of abundance and diversity (Austen 2004). The nematodes play an important role in the function of these systems by aiding in decomposition processes and recycling nutrients (Austen 2004). Several marine nematodes harbor unique microbial diversity in the microenvironments of their body surface (Ott et al. 2004), and bacterial taxa form symbiotic relationships with them (Polz et al. 1998, Moens et al. 2005, Musat et al. 2007). Similar relationships have also been reported in other groups of marine organisms (Van Oppen et al. 2005, Rodriguez-Lanetty et al. 2006).
In terrestrial soil environments, interactions between nematodes and bacteria (Horiuchi et al. 2005, GoodrichBlair 2007) as well as other microbial organisms such as fungi have been more frequently reported. In particular, the level of interaction between nematodes and fungi (relevant to the present study) can be broadly grouped into 4 principal categories: (1) nematodes as fungal predators (Bakhtiar et al. 2001); (2) fungi as predators or parasites of nematodes (Viaene and Abawi 2000); (3) etiological relations between nematodes and fungi (Zahid et al. 2002); and (4) nematodes acting as vectors for fungal spores (Mendoza de Gives et al. 1999). While such interactions occur frequently in the terrestrial environment, there are no reports as yet of fungal and nematode interactions from estuarine and marine environments. 
Fungal 18S rRNA sequences were frequently detected in recent studies developing molecular approaches for the analysis and assessment of marine nematode diversity from the sediments of southwest England, and this has influenced the development of marine nematode specific 18S rRNA primers (Bhadury et al. 2006, P. Bhadury \& M. C. Austen unpubl. data). Since nematode-marine fungal co-amplification has not been reported in the literature, pilot studies were carried out to test the extent of fungal 18S rRNA coamplification along with nematode 18S rRNA from different environmental sediment samples collected in the southwest of England using PCR-based denaturing gradient gel electrophoresis (DGGE).

\section{MATERIALS AND METHODS}

Sediment collection. Sediment samples were collected in June 2004 from various estuarine and marine habitats close to Plymouth in southwest England. Subtidal sediment was sampled using a van Veen grab from muddy and muddy-sand substrates in the Tamar estuary ( 1 to $5 \mathrm{~m}$ depth, $50^{\circ} 24^{\prime} \mathrm{N}, 4^{\circ} 12^{\prime} \mathrm{W}$ ), from Plymouth Sound at Jennycliff (JCF) (10 m depth, $50^{\circ} 20^{\prime} \mathrm{N}, 4^{\circ} 08^{\prime} \mathrm{W}$ ) and Plymouth Breakwater (BW) (15 m depth, $50^{\circ} 20^{\prime} \mathrm{N}, 4^{\circ} 08^{\prime} \mathrm{W}$ ). Intertidal sediment samples were collected by hand from intertidal mud in the Plym estuary (Saltram). All samples were immediately fixed in 11 containers containing 98\% molecular grade ethanol (Hayman).

Nematode and DNA extraction. Nematodes were extracted from sediments with Ludox using the Somerfield et al. (2005) flotation protocol. Subsequently, 16 nematodes were picked out from each environmental site sample under a compound microscope and identified using standard taxonomic methods (Platt \& Warwick 1983, 1988). Following identification, each of the nematodes was individually transferred to $0.5 \mathrm{ml}$ PCR tubes containing $20 \mu \mathrm{l}$ of $0.25 \mathrm{M} \mathrm{NaOH}$ for DNA extraction. DNA was extracted from each nematode following the Bhadury et al. (2006) protocol. The extract was then used for PCR amplification.

Primers for PCR-DGGE analysis. Nematode $18 \mathrm{~S}$ rRNA primers from previous studies (Blaxter et al. 1998, Cook et al. 2005) were tested in the present study. The 2 primers used for PCR amplification were G18S4F (5'-GCT TGT CTC AAA GAT TAA GCC-3') and 22R (5'-GCC TGC TGC CTT CCT TGG A-3'). The length of the amplicon was approximately 400 bp. A $40 \mathrm{bp}$ GC clamp was added to the 5' end of the forward primer (G18FGC) during its synthesis so as to prevent complete denaturation of the amplicons under denaturing conditions during DGGE (Sheffield et al. 1989).
Amplification of 18S rRNA gene for DGGE analysis. DNA extracted from each specimen was amplified in a total volume of $50 \mu \mathrm{l}$ using G18FGC and 22R primers. For PCR parameters see Cook et al. (2005). The PCR products were analysed in $1 \%$ agarose gel prior to DGGE analysis. Control PCR reactions were also set to check for airborne fungal contaminants within the laboratory environment.

DGGE analysis. DGGE analysis was performed on amplified DNA templates using the DCode ${ }^{\mathrm{TM}}$ Universal Detection System (Bio-Rad) according to the manufacturer's instructions. The present study used 25 to $60 \%$ denaturing gradient gels. Gels were loaded with $15 \mu \mathrm{l}$ PCR product amplified from each nematode specimen and subsequently stained with SYBR Gold nucleic acid gel stain (Invitrogen). Electrophoresis was carried out at $60 \mathrm{~V}$ for $16 \mathrm{~h}$ at $60^{\circ} \mathrm{C}$. Gels were visualized and recorded using a gel documentation system (SYNGENE).

Cloning and DNA sequencing. Dominant bands were cut from the denaturing gels, resuspended in $20 \mu \mathrm{l}$ of MilliQ water and left overnight at $4^{\circ} \mathrm{C}$. Subsequently, $2 \mu \mathrm{l}$ from each elute was used as template for PCR amplification using the same set of primers (G18F and 22R). Prior to cloning, purity of the re-amplified bands was checked by electrophoresis in denaturing gels. Re-amplified PCR fragments were cloned using the pGEM-T Easy vector system (Promega). Plasmid DNA containing the inserts were cycle-sequenced using a BigDye Terminator Kit (Applied Biosystems). Cycle sequencing reactions were cleaned using the Wizard Magnesil ${ }^{\mathrm{TM}}$ system (Promega). Sequencing was carried out in both directions using M13F and M13R primers in an ABI Hitachi 3100 Genetic Analyzer. The nematode sequences were then compared with known 18S rRNA sequences from GenBank and EMBL using the BLAST search engine (www.ncbi.nlm. nih.gov/Blast.cgi). Fungal sequences were initially identified by BLAST match and then by FASTA query of the EMBL fungi data subset.

Phylogenetic analysis. A minimum of the top 10 BLAST matches based on our fungal sequences and sequences from possibly related fungal taxa or environmental clones were included and manually aligned using SEAVIEW (Galtier et al. 1996). The alignment was inspected closely to ensure that were no PCR chimaera events. Alignment positions that were high in insertions and/or deletions were removed. An online version of PHYML (PHYlogenetic inferences using Maximum Likelihood) (www.atgc-montpellier.fr/phyml/; Guindon et al. 2005) was used to construct a maximum-likelihood (ML) tree by selecting the general time-reversible (GTR)-based substitution matrix and gamma distribution (Guindon \& Gascuel 2003). The tree was subsequently bootstrapped with 1000 replicates. 


\section{RESULTS}

No amplification of airborne fungal spores was detected in the laboratory during the course of these experiments. In total, 64 nematode specimens from 4 sites were identified based on morphological characters and subsequently the sequences of the $18 \mathrm{~S}$ rRNA amplicons from these specimens separated in the DGGE gels. Sequenced bands from the gels showed 96 to $100 \%$ identity with published nematode $18 \mathrm{~S}$ rRNA sequences held online at GenBank and EMBL. Most of the nematodes were identified as Anoplostoma sp., Atrochromadora sp., Daptonema oxycerca, D. normandicum, D. setosum, Sabatieria pulchra, S. celtica and Terschellingia longicaudata. No co-amplification of fungal 18S rRNA sequences was detected alongside nematode amplicons from the Tamar and Plym sites. In contrast, 12 co-amplified fungal 18S rRNA sequences were detected alongside 16 nematode 18S rRNA sequences in the same denaturing gel from the JCF site. From the BW site, 10 co-amplified fungal $18 \mathrm{~S}$ rRNA sequences were detected alongside 16 nematode 18S rRNA sequences following electrophoresis. The fungal 18S rRNA product consisted of a 355 to $401 \mathrm{bp}$ fragment from the extreme $5^{\prime}$ end of the gene. Three types of fungal 18S rRNA sequences were detected in the present study. FASTA matching of these products gave identities of $>98 \%$ to known fungal taxa in each case (Table 1). Four and 3 sequences from JCF and BW, respectively, belonged to clone type 1, whereas 10 sequences (6 from JCF and 4 from BW) belonged to clone type 2 and 5 sequences ( 2 from JCF and 3 from BW) resembled clone type 3.

The sequences from fungal clone types 1,2 and 3 were further examined through BLAST and FASTA searches and through direct comparisons with potentially related taxa. The highest match was to an un- identified Herpotrichaellaceae sequence with the next closest matches to Rhinocladiella and Exophiala species. These 2 genera are possibly closely related members of the Chaetothyriales (Herpotrichiellaceae), and so the clone type 1 fragment was aligned against the 5 best matches from that order, some further representative species of these genera and representative sequences of the other related fungal orders that were included in the 50 best matches. A phylogenetic tree (Fig. 1) recovered clone type 1 and the 3 best matches in a distinct group within a larger Chaetothyriales clade, and some of these were also represented by marine genera. Sequences from clone types 2 and 3 both showed $98 \%$ similarity over $100 \%$ of the sequence to a range of fungal genera that are all placed in the Hypocreales. In addition, clone types 2 and 3 showed $100 \%$ similarity over $94 \%$ of the sequence to 2 sequences from Verticillium insectorum and V. leptobactrum (Hypocreales). These sequences were included in a phylogenetic analysis with similar sequences from a range of hypocrealean species (Fig. 1). Clone types 2 and 3 were recovered together with the Verticillium sequences in a distinct clade that consisted of some other Verticillium-like species and other anamorphic fungi with presumed Cordyceps teleomorphs. These were linked to, but distinct from, a group formed largely of species that were pathogens of other fungi. Bootstrap confidence levels were high for these groupings, but generally low across this dataset.

\section{DISCUSSION}

The identified nematode 18S rRNA sequences from these environments matched with observations from previous studies (Cook et al. 2005, Bhadury et al. 2006) and most of these taxa are thought to be dominant in

Table 1. Clone sequence types showing similarity with known fungal sequences from the EMBL database along with respective affiliations

\begin{tabular}{|c|c|c|c|c|}
\hline Clone type & Identification & Coverage & $\%$ similarity & Fungal group \\
\hline \multirow[t]{3}{*}{1} & $\begin{array}{l}\text { Herpotrichiellaceae sp. } \\
\text { (GenBank accession no. EF060620) }\end{array}$ & 99 & 100 & Herpotrichiellaceae, Chaetothyriales \\
\hline & Rhinocladiella aquaspersa & 100 & 98.7 & " \\
\hline & Exophiala oligosperma & 96 & 98.69 & $"$ \\
\hline \multirow[t]{6}{*}{2} & Cordyceps caloceroides & 100 & 98 & Hypocreales, Hypocreomycetidae \\
\hline & Syspastospora parasitica & 100 & 98 & " \\
\hline & Myrothecium roridum $(\times 3)$ & 100 & 98 & $"$ \\
\hline & Tritirachium sp. & 100 & 98 & Incertae sedis \\
\hline & Niesslia exilis & 100 & 98 & Hypocreales, Hypocreomycetidae \\
\hline & Paecilomyces anatarcticus & 100 & 98 & \\
\hline \multirow[t]{3}{*}{3} & Verticillium insectorum & 93 & 99 & Hypocreales, Hypocreomycetidae \\
\hline & Verticillium leptobactrum & 93 & 99 & 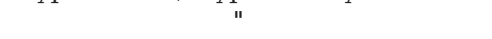 \\
\hline & Paecilomyces fumosoroseus & 93 & 99 & Trichocomaceae, Eurotiales \\
\hline
\end{tabular}


1. Sabatieria sp.

2. Daptonema hirsutum and D. normandicum

3. Terschellingia longicaudata

4. Spirinia parasitifera

5. Viscosia viscosa

6. Parodontophora sp.

7. Oncholaimellus sp.
Elaphocordyceps subsessilis EF469077 $\rightarrow$

Cordyceps gunnii DQ838790

Tolypocladium inflatum AY245674

Cordyceps sphingum AY245673

Metacordyceps liangshanensis EF468961

Phytocordyceps ninchukispora AY245668

Cordyceps gunnii DQ838789 $\rightarrow$

Paecilomyces canadensis AY245666 -

Elaphocordyceps subsessilis EF469077

42 Elaphocordyceps subsessilis EF469124

Cordyceps scarabaeicola AY245663

Cordyceps cicadae $\mathrm{DQ} 838788 \longrightarrow$

63 Geosmithia putterilli $\mathrm{AB} 027150 \rightarrow$ Geosmithia lavendula D14405

- Botryosphaeriales

- Chactothyriales

Lecanorales

$\rightarrow$ Pleosporales

$\rightarrow$ Hypocreales

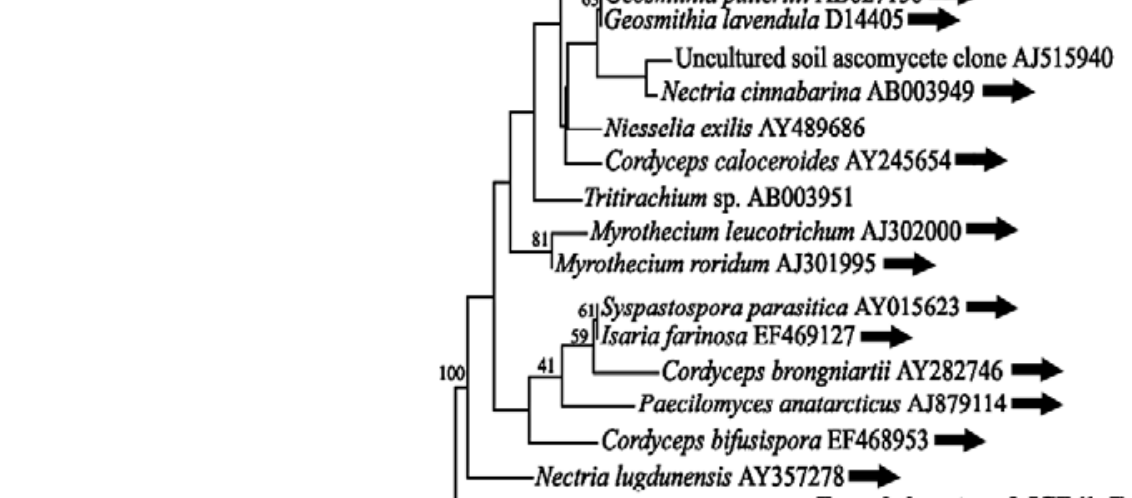

1

100 Paecilomyces javanicus $\mathrm{AB} 09944$

Fungal clone type 2 JCF $(5,6)$, BW $(3,5,6)$

Uncultured fungus clone AY681388

_Uncultured soil fungal clone AM114817

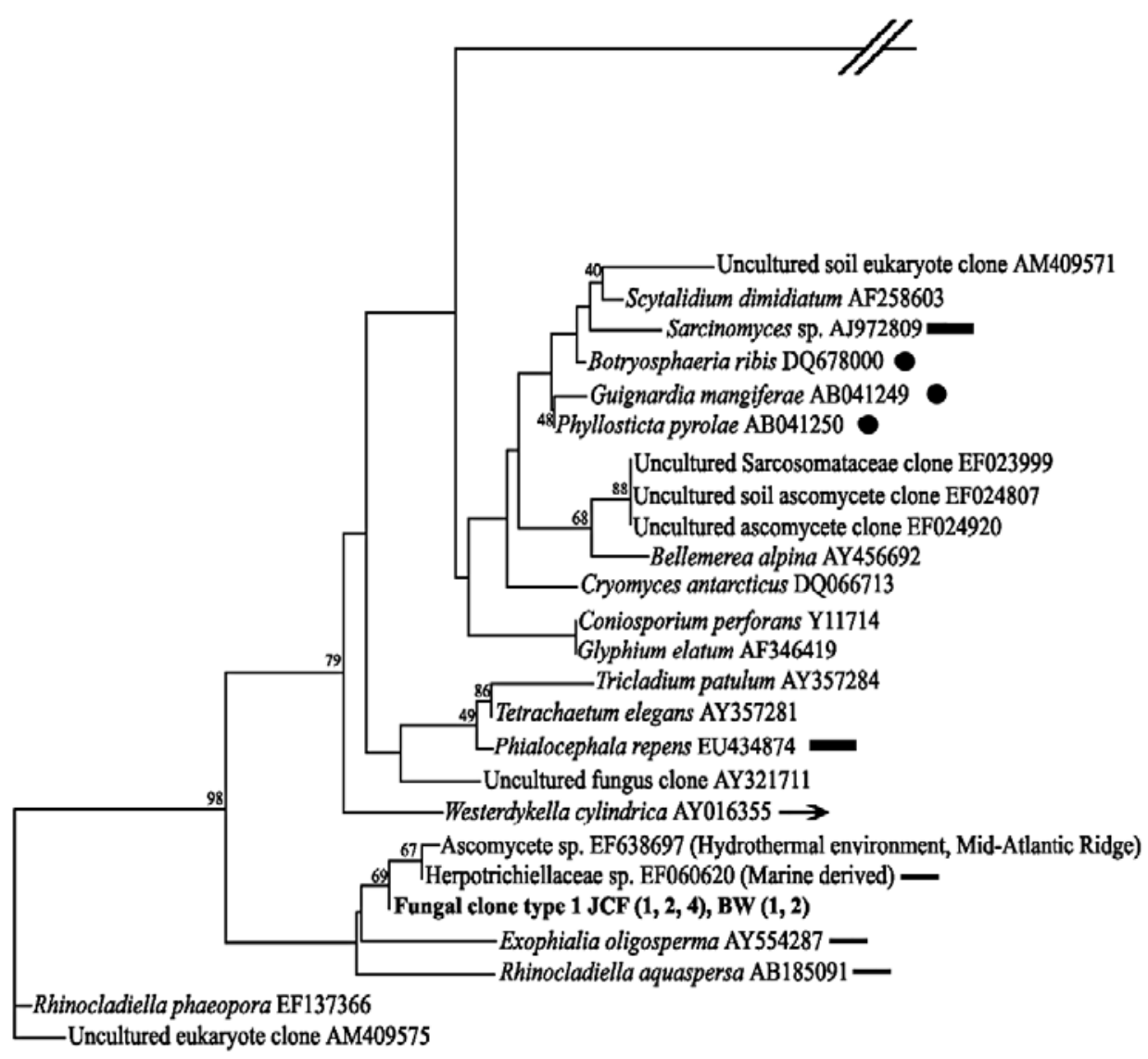

Fig. 1. Maximum likelihood tree showing the relationship between fungal clone sequence types detected from 2 environmental sites and available sequences from databases. JCF: Jennycliff; BW: Breakwater). Numbers next to each fungal clone sequence type $\bullet$ (in bold): corresponding marine nematode taxa from which the amplicon was sequenced (see key). Bootstrap values $>40$ are shown in the tree 
and around the waters of southwest England. However, what is more intriguing is the apparent detection of the fungal 18S rRNA sequences from 2 of the sites. This indicates that the DGGE primers have homologies with nematode as well as fungal 18S rRNA regions and are not nematode-specific. At the JCF and BW sites, the fungal sequences were only detected in nematode $18 \mathrm{~S}$ rRNA amplicons of Sabatieria sp., Daptonema hirsutum, D. normandicum, Terschellingia longicaudata, Spirinia parasitifera, Viscosia viscosa, Parodontophora sp. and Oncholaimellus sp. This suggests that the fungal sequence types (and the original fungi) may be restricted to certain groups of nematodes. Because these sequences were detected alongside specific nematode taxa and previous studies have demonstrated interactions between nematodes and other microorganisms (see 'Introduction'), we therefore suggest that the fungal amplicons may represent a true fungal-nematode ecological association rather than transient environmental contamination. The primers tested in the present study were designed for nematode $18 \mathrm{~S}$ rRNA amplification and it is therefore more likely that greater fungal diversity remains to be explored. Implementation of taxonomically broad fungal specific primers as evaluated in other studies (Vandenkoornhuyse et al. 2002, Bass et al. 2007) may reveal higher ribotype diversity when tested in marine nematodes.

The 5' region of the $18 \mathrm{~S}$ gene is relatively conserved in fungi, with this gene having been used for crossphyla phylogenetic studies (e.g. Berbee \& Taylor 2001), and so high scores would be expected in similarity searches. Despite this conservation, there is sufficient variability to discriminate down to the levels of orders and families. This level of discrimination is not uncommon in fungal molecular diversity studies (e.g. Lynch \& Thorn 2006), and is apparent with the fungal sequences obtained here, where all significant matches for each sequence are closely related fungal genera.

Clone type 1 was clearly assigned to the Herpotrichiellaceae, with the best match being an unidentified sequence from this family isolated from a marine alga (EMBL accession no. EF060620). Clone type 1 and this sequence were clearly placed within the Chaetothyriales in the tree. This order consists of fungi that may show annelidic or sympodial morphology and some members are known to be anamorphs of the genus Capronia. All of the anamorphic genera are considered to be polyphyletic and both Rhinocladiella aquaspersa and Exophiala oligosperma were recovered together in the E. spinifera clade by de Hoog et al. (2003). These fungi are members of a group often referred to loosely as black yeasts. They are commonly isolated from a wide range of environmental samples and some species can cause mycotic infections in humans and other animals. Other species such as $E$. castellanii (syn. R. mansonii) have been isolated from nematode eggs (de Hoog \& Hermanides-Nijhof 1977).

Clones 2 and 3 both identify well with the Hypocreales, and the best matches include genera frequently found in soil or as pathogens or parasites of soil-associated invertebrates and fungi. Many of these species are closely related and there are numerous synonyms and transfers between the genera. The rRNA sequences show very high levels of conservation and it is generally not possible to differentiate between the different anamorphic genera from 18S sequences (Bridge et al. 2005). Among the near matches, Cordyceps spp. are generally associated with invertebrate hosts and one Cordyceps anamorph, Hirsutella, contains a number of nematode pathogenic species (see Nikoh \& Fukatsu 2000, Seifert \& Boulay 2004). The species of Myrothecium included in the best matches is generally associated with plant material, but the related $M$. verrucaria has been used to develop the commercial nematicide DiTera ES (Spooner \& Roberts 2005). More specifically, the sequences of clone types 2 and 3 were recovered in a small group of species within the Hypocreales with Verticillium or Verticillium-like anamorphs. The nematodederived clones were most similar to $V$. insectorum and $V$. leptobactrum, each of which is only represented by a single 18S rRNA sequence in GenBank. Both of these species have been isolated from a number of hosts and environmental samples, including Lepidoptera, human nails and air. $V$. insectorum has also been recovered from the slime mould Trichia, and V. leptobactrum is reported from mushrooms, Daphnia, various plant materials and nematodes (see www.cbs.knaw.nl/databases; Humber \& Hansen 2005).

Although the identifications obtained here for the fungal sequences are limited to only a short part of the 18S rRNA gene, there is sufficient taxonomic information to identify them to at least order level as members of the Exophiala spinifera clade of the Chaetothyriales and the Verticillium-like taxa of the Hypocreales. The precise location and function of these fungi in the marine nematode environment is presently unclear. The detection of fungal sequences from individual nematode specimens may lead us to assume that these are associated with the nematode tissue or part of the gut contents. Many nematodes are mycophagous and are known to ingest fungal hyphae or propagules. Another possibility is that the sequences may be derived from fungal pathogens. In general, both Exophiala and Verticillium species have strong extracellular protease activity (see Samuels et al. 1990), as might be expected for a pathogen. The identifications obtained here are to orders and groups of fungi that are known to contain isolates which are pathogenic to at least one stage of the nematode life cycle. However, a 
fuller interpretation is limited, as the recovery of DNA sequences does not necessarily indicate that viable fungal propagules were present.

Fungal associations have been also recorded in other groups of organisms. For example, fungal associations were detected with healthy and decaying brown seaweed Fucus serratus thallii over a long-term period using the DGGE approach, and most of the isolates shown were similar to Lulworthia, Lindra, Sigmoidea/ Corollospora, Acremonium/Emericellopsis-like and other ribotypes (Zuccaro et al. 2008). There are also reports of fungal associations with other marine algae and halophytes, and the majority of these fungi belonged to either Ascomycota or Deuteromycota (Kohlmeyer \& Volkmann-Kohlmeyer 2001, Buchan et al. 2003, Zuccaro \& Mitchell 2005). Several studies have also reported the presence of endophytic mycophycobionts associated with brown seaweeds (Kohlmeyer \& Kohlmeyer 1979, Kohlmeyer \& Volkmann-Kohlmeyer 1998). Marine fungal associations on decaying woods, seagrasses, calcareous and chitinous substrates as well as other marine organisms are also well reported, and the majority of the isolated fungal strains were within the Deuteromycota or Basidiomycota (Pivkin 2000, Prasannarai \& Sridhar 2001, Sarma \& Hyde 2001, Golubic et al. 2005). Additionally, isolates from the fungal genus Cladosporium (Ascomycota) have been identified from varying marine substrates (Kohlmeyer \& Kohlmeyer 1979, Kohlmeyer \& Volkmann-Kohlmeyer 1998). The fungal clones identified in the present study can also be broadly grouped within the Ascomycota and Deuteromycota, and therefore show similarities in terms of taxonomic groupings with previous studies.

It appears that the fungi associated with marine nematodes comprise species and groups similar to those found in the terrestrial environment. Because these fungal sequences were detected only in certain species and at only 2 of the 4 sites sampled, we can speculate that some marine nematodes may be mycophagous. The present study also highlights the need to develop more robust nematode-specific PCR primers for molecular diversity studies, which we have addressed in 2 studies (Bhadury et al. 2006, P. Bhadury and M. C. Austen unpubl. data). New avenues of research, in particular gut content analyses of nematodes using molecular tools, would also be desirable. Overall, the present study is the first to detect fungal sequences in parallel with marine nematode 18SrRNA sequences. This suggests new routes to understanding the feeding ecology of coastal and estuarine nematodes.

Acknowledgements. P.B. acknowledges Plymouth Marine Laboratory for the provision of a PhD Studentship. We would like to thank the 3 anonymous reviewers for their helpful comments. This is a contribution to the Plymouth Marine Laboratory Biodiversity and Sustainable Ecosystems theme.

\section{LITERATURE CITED}

Austen MC (2004) Natural nematode communities are useful tools to address ecological and applied questions. Nematol Monogr Perspect 2:1-17

Bakhtiar Y, Miller D, Cavagnaro T, Smith S (2001) Interactions between two arbuscular mycorrhizal fungi and fungivorous nematodes and control of the nematode with fenamifos. Appl Soil Ecol 17:107-117

Bass D, Howie A, Brown N, Barton H and others (2007) Yeast forms dominate fungal diversity in the deep oceans. Proc R Soc Lond B Biol Sci 274:3069-3077

Berbee ML, Taylor JW (2001) Fungal molecular evolution: gene trees and geologic time. In: McLaughlin DJ, McLaughlin EG, and Lemke PA (eds) The Mycota: systematics and evolution, Part B. Springer, Berlin, p 229-245

Bhadury P, Austen MC, Bilton DT, Lambshead PJD, Rogers AD, Smerdon GR (2006) Development and evaluation of a DNA-barcoding approach for the rapid identification of nematodes. Mar Ecol Prog Ser 320:1-9

> Blaxter ML, De Ley P, Garey JR, Liu LX and others (1998) A molecular evolutionary framework for the phylum Nematoda. Nature 392:71-75

Bridge PD, Clark MS, Pearce DA (2005) A new species of Paecilomyces isolated from the Antarctic springtail Cryptopygus antarcticus. Mycotaxon 92:213-222

> Buchan A, Newell SY, Butler M, Biers EJ, Hollibaugh JT, Moran MA (2003) Dynamics of bacterial and fungal communities on decaying salt marsh grass. Appl Environ Microbiol 69:6676-6687

Cook AA, Bhadury P, Debenham NJ, Meldal BHM and others (2005) Denaturing gradient gel electrophoresis as a tool for identification of marine nematodes. Mar Ecol Prog Ser 291:103-113

de Hoog GS, Vicente V, Caligiorne RB, Kantarcioglu S, Tintelnot K, Gerrits van den Ende AHG, Haase G (2003) Species diversity and polymorphism in the Exophiala spinifera clade containing opportunistic black yeast-like fungi. J Clin Microbiol 41:4767-4778

de Hoog GS, Hermanides-Nijhof EJ (1977) The black yeasts and allied Hyphomycetes. Mycologia 69:1242-1244

Galtier N, Gouy M, Gautier C (1996) SEAVIEW and PHYLO_WIN: two graphic tools for sequence alignment and molecular phylogeny. Comput Appl Biosci 12: $543-548$

Golubic S, Radtke G, Campion-Alsumard TL (2005) Endolithic fungi in marine ecosystems. Trends Microbiol 13:229-235

Goodrich-Blair H (2007) They've got a ticket to ride: Xenorhabdus nematophila-Steinernema carpocapsae symbiosis. Curr Opin Microbiol 10:225-230

Guindon S, Gascuel O (2003) A simple, fast and accurate method to estimate large phylogenies by maximumlikelihood. Syst Biol 52:696-704

Guindon S, Lethiec F, Duroux P, Gascuel O (2005) PHYML Online: a webserver for fast maximum likelihood-based phylogenetic inference. Nucleic Acids Res 33:W557-W559

> Horiuchi J, Prithiviraj B, Bais HP, Kimball BA, Vivanco JM (2005) Soil nematodes mediate positive interactions between legume plants and rhizobium bacteria. Planta 222: $848-857$

Humber RA, Hansen KS (2005) ARSEF INDEX: fungus-hostlocation. USDA-ARS Plant Protection Research Unit, Ithaca, NY

Kohlmeyer J, Kohlmeyer E (1979) Marine mycology, the higher fungi. Academic Press, New York

Kohlmeyer J, Volkmann-Kohlmeyer B (1998) Mycophycias, a new genus for the mycobiont of Apophlaea, Ascophyllum 
and Pelvetia. Systema Ascomycetum 16:1-7

Kohlmeyer J, Volkmann-Kohlmeyer B (2001) Fungi on Juncus roemerianus: new coelomycetes with notes on Dwayaangam junci. Mycol Res 105:500-505

Lynch MDJ, Thorn RG (2006) Diversity of Basidiomycetes in Michigan agricultural soils. Appl Environ Microbiol 72: 7050-7056

Mendoza de Gives P, Davies KG, Morgan M, Behnke JM (1999) Attachment tests of Pasteuria penetrans to the cuticle of plant and animal parasitic nematodes, free living nematodes and srf mutants of Caenorhabditis elegans. J Helminthol 73:67-71

Moens T, dos Santos GAP, Thompson F, Swings J, FonsêcaGenevois V, Vincx M, De Mesel I (2005) Do nematode mucus secretion affect bacterial growth? Aquat Microb Ecol 40:77-83

Musat N, Giere O, Gieseke A, Thiermann F, Amann R, Dubilier N (2007) Molecular and morphological characterization of the association between bacterial endosymbionts and the marine nematode Astomonema sp. from the Bahamas. Environ Microbiol 9:1345-1353

Nikoh N, Fukatsu T (2000) Interkingdom host jumping underground: phylogenetic analysis of entomoparasitic fungi of the genus Cordyceps. Mol Biol Evol 17:629-638

Ott J, Bright M, Bulgheresi S (2004) Symbioses between marine nematodes and sulfur-oxidizing chemoautotrophic bacteria. Symbiosis 36:103-126

Pivkin MV (2000) Filamentous fungi associated with holothurians from the Sea of Japan, off the Primorye coast of Russia. Biol Bull 198:101-109

Platt HM, Warwick RM (1983) Free-living marine nematodes. I. British Enoplids. Cambridge University Press, Cambridge

Platt HM, Warwick RM (1988) Free-living marine nematodes. II. British Chromadorids. Brill/Backhuys, Leiden

Polz MF, Harbison C, Cavanaugh CM (1998) Diversity and heterogeneity of epibiotic bacterial communities on the marine nematode Eubostrichus dianae. Appl Environ Microbiol 65:4271-4275

Prasannarai K, Sridhar KR (2001) Diversity and abundance of higher marine fungi on woody substrates along the west coast of India. Curr Sci 81:304-310

Rodriguez-Lanetty M, Phillips WS, Weis VM (2006) Transcriptome analysis of a cnidarian-dinoflagellate mutualism reveals complex modulation of host gene expression.

Editorial responsibility: Judith Grassle,

New Brunswick, New Jersey, USA
BMC Genomics 7:23

Samuels RI, Charnley AK, St Leger RJ (1990) The partial characterisation of endoproteases and exoproteases from three species of entomopathogenic entomophthorales and two species of deuteromycetes. Mycopathologia 110: $145-152$

Sarma VV, Hyde KD (2001) A review on frequently occurring fungi in mangroves. Fungal Divers 8:1-34

Seifert KA, Boulay H (2004) Hirsutella uncinata, a new hyphomycete from Australia. Mycologia 96:929-934

> Sheffield VC, Cox DR, Lerman LS, Myers RM (1989) Attachment of a 40-base-pair $\mathrm{G}+\mathrm{C}$-rich sequence (GC-clamp) to genomic DNA fragments by the polymerase chain reaction results in improved detection of single-base changes. Proc Natl Acad Sci USA 86:232-236

Somerfield PJ, Warwick RM, Moens T (2005) Meiofauna techniques. In: Eleftheriou A, McIntyre AD (eds) Methods for the study of marine benthos, 3rd edn. Blackwell Science, Oxford, p 229-272

Spooner BM, Roberts P (2005) Fungi. The New Naturalist Library, Collins, Romsey

Van Oppen MJ, Mieog JC, Sanchez CA, Fabricius KE (2005) Diversity of algal endosymbionts (zooxanthellae) in octocorals: the roles of geography and host relationships. Mol Ecol 14:2403-2417

Vandenkoornhuyse P, Baldauf SL, Leyval C, Straczek J, Young JPW (2002) Extensive fungal diversity in plant roots. Science 295:2051

Viaene NM, Abawi GS (2000) Hirsutella rhossiliensis and Verticillium chlamydosporium as biocontrol agents of the root-knot nematode Meloidogyne hapla on lettuce. J Nematol 32:85-100

Zahid MI, Gurr GM, Nikandrow A, Hodda M, Fulkerson WJ, Nicol HI (2002) Effects of root- and stolon-infecting fungi on root-colonizing nematodes of white clover. Plant Pathol $51: 242-250$

Zuccaro A, Mitchell JI (2005) Fungal communities of seaweeds. In: Dighton J, White JF Jr, Oudemans P (eds) The fungal community, 3rd edn. CRC Press, New York, p 533-579

Zuccaro A, Schoch CL, Spatafora JW, Kohlmeyer J, Draeger S, Mitchell JI (2008) Detection and identification of fungi intimately associated with the brown seaweed Fucus serratus. Appl Environ Microbiol 74:931-941

Submitted: January 21, 2008; Accepted: February 19, 2009

Proofs received from author(s): March 20, 2009 